\title{
Time-dependent reliability analyses of prestressed concrete girders strengthened with CFRP laminates
}

\author{
D. Dias-da-Costa ${ }^{\mathrm{a}, \mathrm{b}, *}$, L.A.C. Neves ${ }^{\mathrm{c}}$, S. Gomes ${ }^{\mathrm{b}}$, S.A. Hadigheh ${ }^{\mathrm{a}}$, P. Fernandes ${ }^{\mathrm{d}}$ \\ ${ }^{a}$ School of Civil Engineering, The University of Sydney, Sydney, NSW 2006, Australia \\ ${ }^{\mathrm{b}}$ ISISE, Department of Civil Engineering, University of Coimbra, Rua Luís Reis Santos, 3030-788 Coimbra, Portugal \\ ${ }^{\mathrm{c}}$ Centre for Risk and Reliability Engineering, University of Nottingham, Faculty of Engineering, University Park, United Kingdom \\ ${ }^{\mathrm{d}}$ Civil Engineering Department, Instituto Politécnico de Leiria, Portugal
}

\section{A R T I C L E I N F O}

\section{Keywords:}

CFRP laminate degradation

Prestressed girder

Time-dependent reliability

Spatial variability

Corrosion

Ditlevsen bounds

\begin{abstract}
A B S T R A C T
This paper presents a time-dependent reliability analysis of prestressed concrete girders subjected to degradation caused by pitting corrosion. The procedure presented includes the effects of both spatial and temporal pitting corrosions on prestressing steel, as well as the degradation of the strengthening CFRP laminate used for the rehabilitation of the member. Results indicate that the correlation of corrosion in different segments of the prestressing tendons impacts on the computed safety index for the deteriorated structure. Ditlevsen bounds are proposed for a better approximation of the correlation between failure modes in the spatial discretisation. Results show that such approach produces adequate estimates of the reliability index over the full range of analysis in comparison with other tested models. It is also observed that the degradation of the CFRP laminates does not affect the reliability as significantly as corrosion, and that traffic loads, models uncertainties, corrosion error and corrosion rate are the most relevant variables in the analysis, followed by prestressing strength and concrete cover. The significance of the variables changes with time: the corrosion rate, corrosion model error and concrete cover increase in importance with the development of corrosion, whereas traffic loads become gradually less important.
\end{abstract}

\section{Introduction}

Many highway networks have been progressively expanding over the last decades to accommodate the growth of road traffic and meet the demands of modern cities. Such expansion required the construction of a significant number of bridges, many of which using precast prestressed concrete (PC) girders. This structural system has several advantages over other solutions, such as the speed of construction, the low cost, and the quality control from precast industry.

With ageing, however, many PC girders are vulnerable to corrosion of reinforcements that progressively reduces the structural strength, and can eventually lead to complete degradation. Generalised corrosion can occur when a large area of the structure is subjected to carbonation. The pronounced corrosion at specific localisations, also known as pitting, can spread along the reinforcement bars and is more likely to be caused by chloride attack [1]. Several factors influence the corrosion rate, such as the water-cement ratio, cement composition, aggregate size, construction practices, concrete cover, environmental conditions, admixtures, temperature, and $\mathrm{pH}$ variation due to carbonation, among others $[1,2]$. Predicting the impact of these parameters - in both time and space - is a complex process. For this reason, a probabilistic approach can be very useful, since it allows explicit consideration of the uncertainty in reliability analysis.

Most time-dependent flexural reliability studies of RC beams in the literature considered steel reinforcement and pitting as time-dependent random variables [2-5]. Even though those studies generally show that the reliability strongly decreases with corrosion, a typical simplification consists in assuming pitting to be concentrated at the mid-span section. Thus, the spatial spread over the length of reinforcement is neglected.

Stewart [6] studied the flexural time-dependent reliability of RC beams including the spatial variability. This was achieved by dividing the structural element into several segments, and for each segment, different levels of pitting corrosion were randomly included to simulate the non-homogeneous process along the beam. Structural reliability was computed considering a series system. A similar procedure was also adopted by several other researchers [7-13], showing that the probabilities of failure considering series reliability are higher when compared with the probabilities obtained based only on the most

\footnotetext{
* Corresponding author at: School of Civil Engineering, The University of Sydney, Sydney, NSW 2006, Australia.

E-mail address: daniel.diasdacosta@sydney.edu.au (D. Dias-da-Costa).
} 
unfavourable situation, i.e., the failure of the reinforcement at the midspan. When a series system is considered, the reliability of the beam assumes failure to occur at any segment. Since the failure of any segment on such system directly causes the failure of the beam, the probability of failure increases. This simple analysis shows the relevance of obtaining a reliable procedure to correlate the segments of corroded steel reinforcement, particularly for structures that rely heavily on prestressing steel.

A competitive solution available to upgrade and strengthen degraded RC girders uses fibre reinforced polymer (FRP) composites applied as externally bonded reinforcement (EBR). Compared to other techniques, it has cost effectiveness, low weight, ease of installation, and the ability to quickly restore the structural capacity [14]. Focusing on the condition assessment of bridge girders upgraded with post-tensioned near-surface-mounted CFRP laminates, Kim, Kang [15] developed a computational model for the bridge girders over an extended lifespan showing that the strengthening composite becomes more effective as the flexure stiffness of the girders decreases with damage. A probabilistic model for the flexural capacity of beams strengthened with prestressed CFRP laminates was developed by Liu, Peng [16] considering all possible failure modes. A time-dependent reliability study targeting shear fracture of reinforced concrete beams strengthened with CFRP laminates in aggressive environments was carried out by Firouzi, Taki [17] and highlighted the importance of corrosion for the occurrence of difference fracture modes. Other time-dependent reliability studies where the specimens are strengthened when safety becomes unacceptable can be mentioned, namely the ones from Ali, Bigaud [18], Bigaud and Ali [19] and Guo, Chen [20]. The first authors performed a reliability analysis of reinforced concrete highway bridges strengthened with CFRP laminates exposed to aggressive environments confirming that the most significant deterioration factor is the corrosion of reinforcements. The other two studies are also relevant to the current work, with Bigaud and Ali [19] addressing concrete bridge girders strengthened with CFRP laminates with $15 \mathrm{~m}$ span, without prestressing steel and designed with AASHTO LRFD [21], whereas Guo, Chen [20] studied bridges designed with GB/T50283 Chinese code, based on a box-girder cross section for longer spans.

The work presented in this paper addresses outdated bridge girders built in small Western European cities several decades ago, with medium to small spans. Many of these structures are currently needing repair due to corrosion and an upgrade to meet current design standards. The study of the degradation, strengthening and subsequent performance of the bridge girders presented is new and relevant to many countries, since the current widely adopted design codes are often more demanding than previous local standards [22]. Also, given that the girders being studied are heavily prestressed, the reliability analyses target the role of the corroded prestressing steel before and after strengthening, together with the interaction with the CFRP laminates.

Reliability studies are frequently based on an idealised reduction of the area of steel reinforcements at mid-span or on series system reliability analysis [7-13]. Given that corrosion of prestressing bars varies significantly along the length, an innovative approach is proposed in the current paper using the Ditlevsen bounds to tackle the spatial interaction between corroded segments in temporal reliability analyses and to improve the estimates of the probability of failure for bridge girders strengthened with CFRP laminates. The Ditlevsen bounds provide a very good approximation to the probability of failure for system series. Given the sensitivity of the prestressed structure to corrosion, this approach seems quite promising and directly contributes to the field of reliability analysis. The uncertainties for load and resistance models, the error associated with the corrosion model, and both the initiation and propagation stages of corrosion, are also considered.

\section{Case study-PC girder}

The girder selected for analysis in a rehabilitation scenario is part of

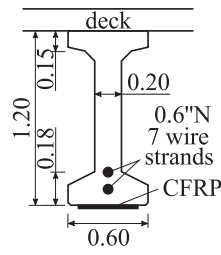

(a)

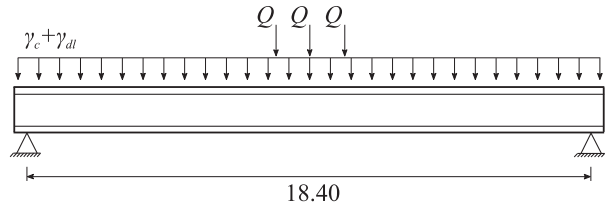

(b)
Fig. 1. Case study: (a) transversal section; and (b) longitudinal section and loading (unless otherwise state, dimensions are in ' $\mathrm{m}$ ').

a simply supported bridge with two traffic lanes and two side-walks in Portugal, as represented in Fig. 1. The design of the initially unstrengthened structure was done according to Portuguese national codes - REBAP [23] and RSA [24] - which were the standards in place just before the new European codes took place. The latter code is significantly more demanding, as can be seen in in Appendix A. Even though the bridge has three girders, only the most critical is herein selected for reliability analyses. A value of $10.37 \mathrm{kN} / \mathrm{m}$ is assumed for the dead-loads in addition to the self-weight, whereas the traffic loads, $Q$, are $200 \mathrm{kN}$ in the original design [24]. The concrete grade is C35/45 EN 1992-1-1 [25], which corresponds to a characteristic compressive strength, $f_{c k}$, of $35 \mathrm{MPa}$, and a mean compressive strength, $f_{c m}$, of $43 \mathrm{MPa}$ at 28 days of age. Two prestressing bonded strands of grade Y1860S prEN 10138-3 [26] with a characteristic tensile strength, $f_{p k}$, of $1,860 \mathrm{MPa}$ are used as active reinforcement, each with two $0.6 \mathrm{in}$ sevenwire steel strand considered submitted to a tension of 1,200 MPa after the long-term losses.

The strengthening of the PC girder is based on Carbon FRP (CFRP) 'CFK 150/2000' laminates according to Eurocodes, namely EN 1990 [27], EN 1991-2 [28] and EN 1992-2 [29]. The laminates are glued to the bottom flange along their length and anchored to the concrete girder at both ends using steel plates. The ultimate load capacity of the CFRP-strengthened girders is determined using an analytical model with the non-linear stress-strain relationship for concrete defined in the EN 1992-2 [29] (Fig. 2):

$\frac{\sigma_{c}}{f_{c}}=\frac{k \eta-\eta^{2}}{1+(k-2) \eta}$

with

$\eta=\frac{\varepsilon_{c}}{\varepsilon_{c 1}}$ and $k=1.05 E_{c} \frac{\left|\varepsilon_{c 1}\right|}{f_{c}}$

where $\sigma_{c}$ and $\varepsilon_{c}$ are the compressive stress and strain for concrete, $\varepsilon_{c 1}$ is the strain at peak stress according to EN 1992-2 [29], $E_{c}$ is the secant Young's modulus of concrete, and $f_{c}$ is the concrete cylinder compressive strength. In addition, the tensile strength of the concrete is neglected.
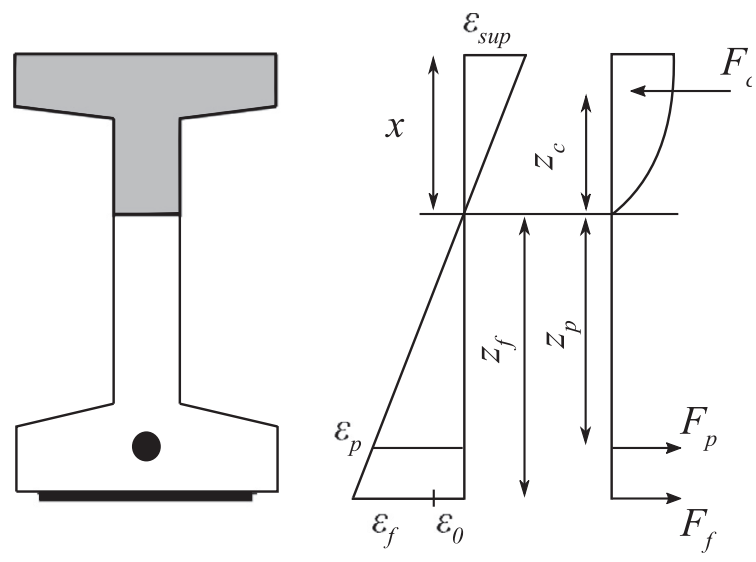

Fig. 2. Stress-strain diagram for cross-sectional analysis. 
The analytical model assumes a linear strain distribution over the depth of the girder and that plane sections remain plane while bending. The bending moment is calculated by:

$M=F_{c} z_{c}+F_{p} z_{p}+F_{f} z_{f u}$

where $F_{c}$ is the compressive force in concrete, $z_{c}$ is the distance from the neutral axis, $x$, to the concrete force, $F_{p}$ is the force due to prestressing strands, $z_{p}$ is the distance between the prestressing strands and the neutral axis, $F_{f}$ is the force due to CFRP laminates and $z_{f u}$ is the distance from the CFRP laminates to the neutral axis.

The stress state when CFRP laminates are to be installed is very important for serviceability purposes, in which case the girders may need to be lifted to partially release dead-loads and allow the strengthening to be more effective. Given that focus in this paper is given to the ultimate limit bending state, a conservative analysis is adopted in which only the dead-loads are present during the strengthening operation. An iterative process is used to find the equilibrium of forces by progressively searching the location of the neutral axis in two stages of analysis. In a first stage, the equilibrium is checked for deadloads only (before the application of CFRP laminates), such that the strain at the soffit before strengthening the girder can be assessed. This strain is not used to engage the CFRP laminates and sets a conservative value for the maximum strain that can be mobilised after installing the CFRP laminates quantified in a second stage of analysis. During this second stage, the required area of the CFRP laminates is determined to assure that the ultimate bending moment capacity of the cross-section matches the design moment for the fully loaded girder. All possible situations are accounted for, e.g. failure after the yielding of the prestressing steel through the CFRP laminate or concrete crushing, and prestressing strands reaching $0.1 \%$ proof stress simultaneously with the CFRP laminate.

It should be mentioned that a recent study addressing advanced non-linear models developed for simulating the interaction of concrete cracks with local debonding of the CFRP laminate, including bond between steel and concrete, and CFRP laminates and concrete, showed the approximations made in simplified analytical models - such as the one herein adopted - to be acceptable [30].

\section{Time-dependent degradation models}

One of the major concerns in prestressing steel structures is related with corrosion, since it could reduce the structural strength and serviceability conditions quickly to an unacceptable level [1]. In the case of CFRP strengthened structures, the degradation of the composite is also an important factor that needs to be evaluated. The following section describes the degradation models adopted in this research for prestressing steel and CFRP laminates.

\subsection{Corrosion of prestressing element}

Pitting corrosion can easily occur in prestressing steel reinforcements due to chloride-induced contamination and can vary in space and time [31]. The time-dependent model proposed by Val and Melchers [3] is adopted here. Accordingly, pits are assumed to propagate in hemispherical forms, with a radius of $p$ estimated by:

$p(t)=0.0116\left(t-t_{i}\right) i_{c} R$

where $t$ is time in yrs, $t_{i}$ is the corrosion initiation time in yrs, $i_{c}$ is the corrosion rate quantified as a current density, and $R$ is the ratio between the maximum pit depth, $P_{\max }$, and the average pit depth, $P_{a v}$ - see representation in Fig. 3.

The area of the pit, $A_{p i t}$, can be quantified as suggested by Val and Melchers [3]:
$A_{p i t}(t)=\left\{\begin{array}{c}A_{1}+A_{2} \text { if } p(t) \leqslant \frac{D_{0}}{\sqrt{2}} \\ \frac{\pi D_{0}^{2}}{4}-A_{1}+A_{2} \text { if } \frac{D_{0}}{\sqrt{2}}<p(t) \leqslant D_{0} \\ \frac{\pi D_{0}^{2}}{4} \text { if } p(t)>D_{0}\end{array}\right.$

with

$$
\begin{aligned}
A_{1} & =0.5\left[\theta_{1}\left(\frac{D_{0}}{2}\right)^{2}-a\left|\left(\frac{D_{0}}{2}\right)-\left(\frac{p(t)^{2}}{D_{0}}\right)\right|\right], A_{1} \\
& =0.5\left[\theta_{2} p(t)^{2}-a\left(\frac{p(t)^{2}}{D_{0}}\right)\right], a=2 p(t) \sqrt{1-\left(\frac{p(t)}{D_{0}}\right)^{2}}, \theta_{1} \\
& =2 \arcsin \left(\frac{2 a}{D_{0}}\right), \operatorname{and} \theta_{2}=2 \arcsin \left(\frac{a}{p(t)}\right)
\end{aligned}
$$

The initiation time, $t_{i}$, is the time necessary for the chloride ions concentration at concrete cover to reach a threshold value, $C_{t h}$, at the contact surface of steel, as shown in Fig. 4. The diffusion equation is solved to obtain the evolution of the chloride concentration with respect to both depth and time, thus allowing to quantify the initiation time for a given $C_{t h}$. Accordingly, Fick's second law can be written as:

$\frac{\partial C(x, t)}{\partial t}=D_{c l} \frac{\partial^{2} C(x, t)}{\partial x^{2}}$,

where $C(x, t)$ is the chloride ion concentration at time $t$ in years, and distance from the surface $x$, and $D_{c l}$ is the chloride diffusion coefficient.

The chloride concentration is given by [2]:

$C(x, t)=C_{s}\left(1-\operatorname{erf} \frac{x}{2 \sqrt{D_{c l} t}}\right)$,

where $C$ is concentration inside concrete for a given time $t$ and depth $x$, $C_{s}$ is the chloride concentration on the concrete surface, erf is the error function, and $D_{c l}$ is the chloride diffusion coefficient. The last coefficient is strongly affected by the time of exposure, temperature and relative humidity [32].

Corrosion can propagate uniformly along the bar and/or concentrate at specific locations. When corrosion extends uniformly to a large area, it is usually denoted as generalised corrosion and is typically due to carbonation. On the other hand, when corrosion is more pronounced on specific locations, it is known as pitting. Pitting is more likely to occur due to chloride attack and is the most common type of corrosion in prestressing steel [31]. Based on the geometry and location of prestressing strands, chloride penetration is herein assumed to progress from the bottom face of the girder. To model the spatial variability of pitting corrosion, the reinforcement is divided into several segments (see Fig. 5) where different pit depths are considered for each segment [6]. The resistance capacity of the girder is determined by considering the tensile capacity of each segment given by the reduced prestressing area according to Eq. (5). The ratio between maximum and average pit depth is randomly generated, such that the pit diameter varies for each segment along the reinforcement.

The discretisation length for each segment should model the distance at which the pitting corrosion influences the structural safety. This length depends on several factors, such as the capacity of the corroded reinforcement to redistribute stresses, the mechanical behaviour of the reinforcement, the development length, and the specific layout and spacing of reinforcements. Values found in the literature typically range between $0.1 \mathrm{~m}$ and $1.0 \mathrm{~m}[6,8-10,12]$. In this paper, the discretisation length is defined based on the observation that the reliability index should not change suddenly at the onset of corrosion. Therefore, a length of $0.45 \mathrm{~m}$ is found by imposing the reliability index calculated using the series system immediately after corrosion has started to match the value obtained without a series system. The discretisation length is kept constant for all analyses.

When evaluating the safety of the concrete beam, the critical effect 


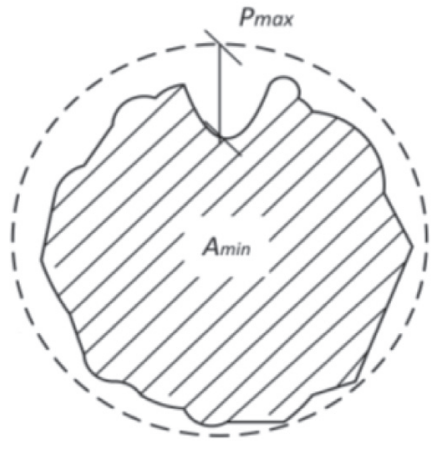

(a)

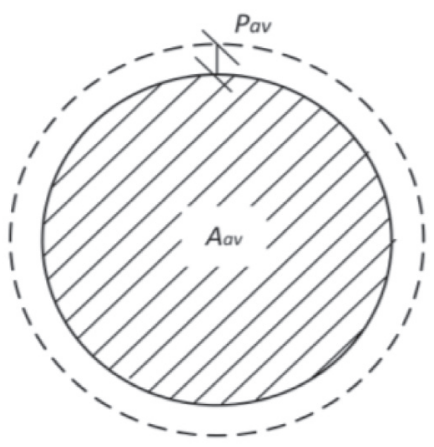

(b)

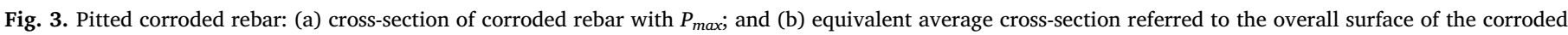
rebar.

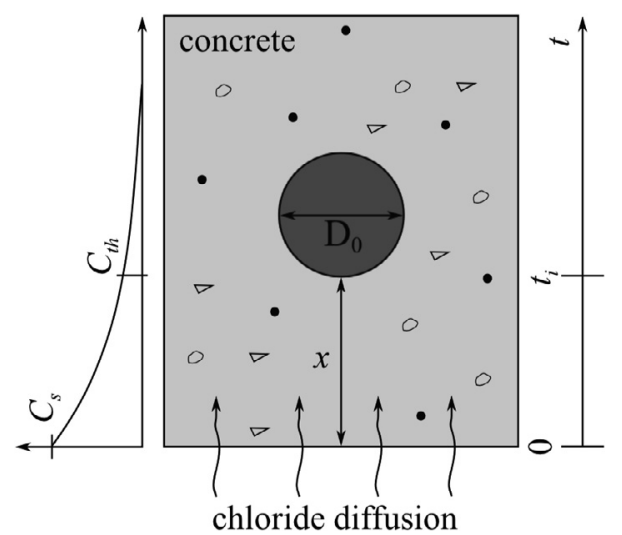

Fig. 4. Chloride diffusion process associated with the corrosion initiation.

of corrosion is the localised reduction of cross-sectional area. Over a given segment, there will be different sections where corrosion is present, but, for the reliability analysis, it is critical to model the maximum corrosion in each segment. This suggests that an extreme distribution might be adequate and this is confirmed by experimental results from concrete specimens subjected to accelerated corrosion tests [8]. All segments are considered statistically independent and the random pit depths, $R$, are generated using a Gumbel distribution calibrated for a similar initial cross-section by Stewart and Al-Harthy [8]. The distribution is defined by:

$R \sim G(\mu, \alpha) ; \mu=5.56 ; \alpha=1.16$.

\subsection{CFRP laminate degradation}

Although several experimental studies addressing the degradation of FRPs can be found in the literature [33-38], probabilistic models are yet to be fully developed and validated for reliability studies. As such, degradation is herein considered using a deterministic approach following the Arrhenius rate equation as suggested by Karbhari and Abanilla [39]. According to the authors, the percentage of strength retention can be expressed by:
$\% f=A \ln (t)+B$,

where $A$ is the degradation rate, and $B$ is a material constant.

Experimental calibration must be used to obtain the parameters mentioned above using accelerated tests to finally express the evolution of the strength retention under real moisture conditions. Given that the authors could not find results available for the type of composite used in this paper, the expression by Ali, Bigaud [18] obtained for a wet-layup system is adopted as an approximation:

$\% f_{f R}=-3.366 \ln (t)+106.07$,

where $\% f_{f R}$ is the percentage of FRP strength retention and $t$ is time in days. A model without any degradation on the CFRP laminate is also considered for comparison purposes.

\section{Proposed reliability analysis procedure}

Please note that in the analyses presented in this paper focus is given to ultimate limit states, in which case the long-term losses associated with pre-stress are included in the pre-stress force corresponding to a stress of 1,200 MPa. The time-dependent reliability analysis procedure proposed includes three main stages - see Fig. 6a.

During the first stage, the degradation caused by corrosion in the unstrengthened girder progresses over time and the corresponding reliability index, $\beta$, is computed for each step. Corrosion is modelled by means of a reduction in the prestressing strand area over time caused by the pit depths along the beam. Unacceptable structural safety is found when the reliability index reaches a minimum threshold, $\beta_{\min }$. Since this threshold is not provided in the Eurocodes, 2.5 is adopted, which is the same value used in the load and resistance rating provisions in AASHTO [40] for checking the safety of existing bridges [41].

Failure is defined when the random structural resistance, $R$, is lower than the current random load demand, $S$ [42-44]. The relationship $R-S$ (to be defined ahead) is the limit state function setting the boundary that separates acceptable and unacceptable structural performance depending on the random variables. Graphically, the probability of failure corresponds to the grey volume represented in Fig. 7a if only two variables are considered, whereas the target reliability index geometrically measures the minimum distance from the origin to the

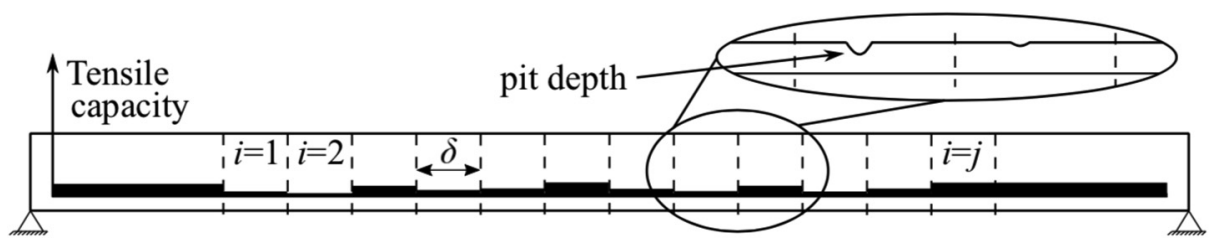

Fig. 5. Spatial tensile capacity of the girder. 


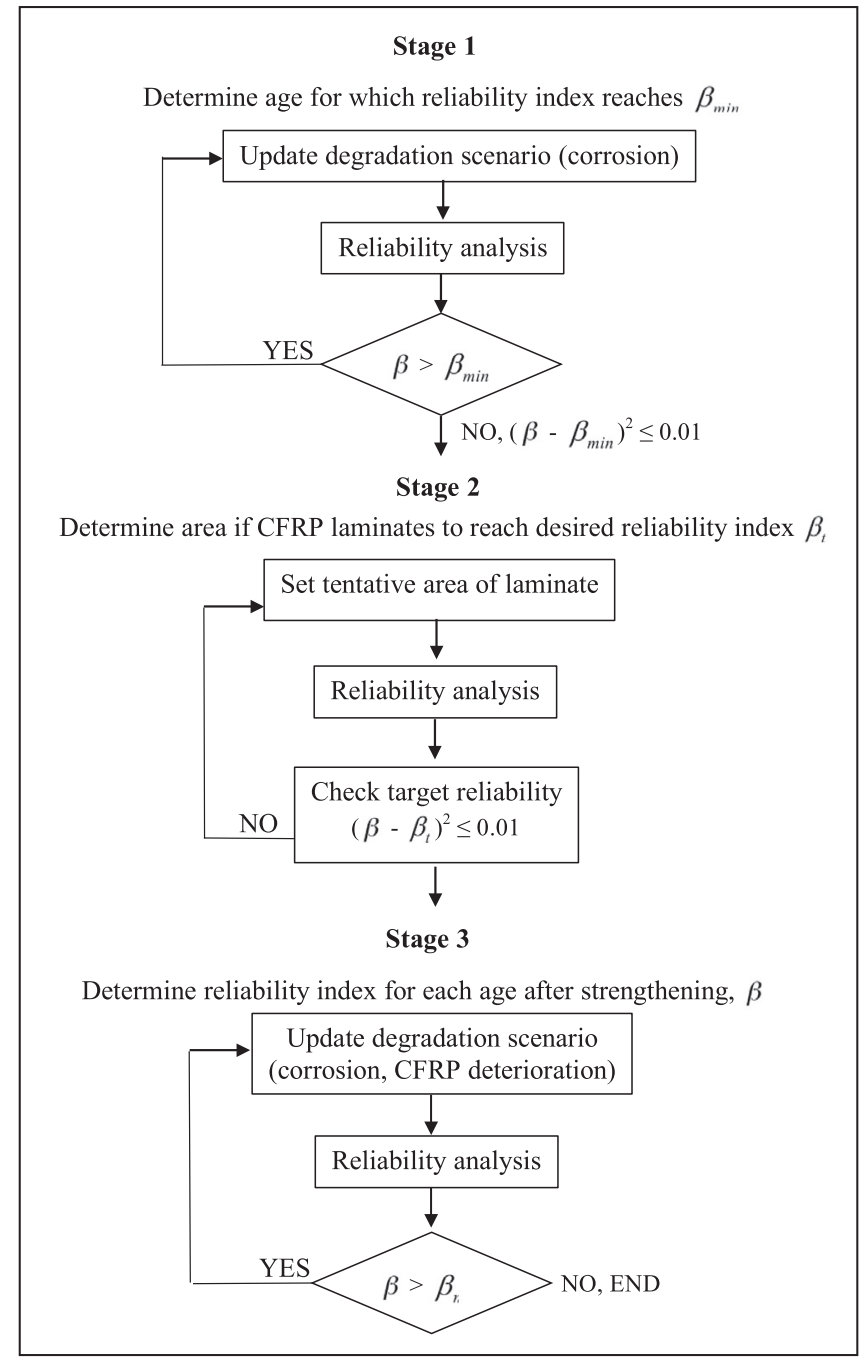

(a)

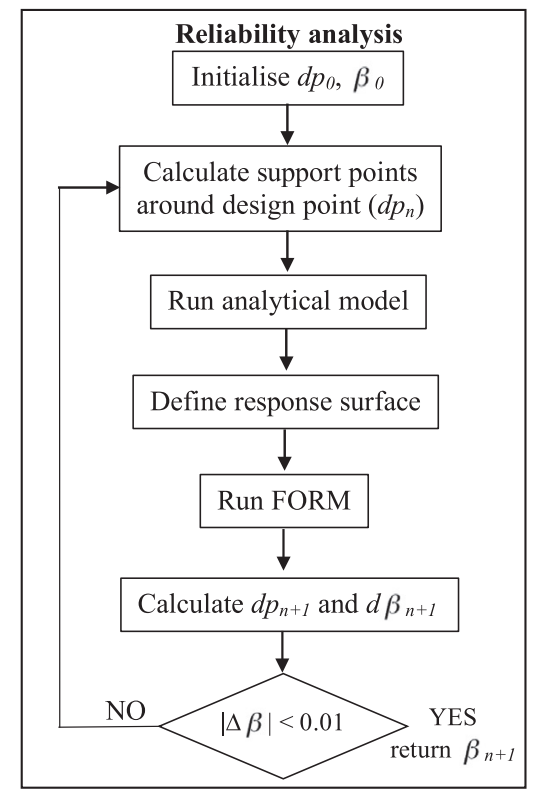

(b)

Fig. 6. Flow chart describing the: (a) stages of analysis; the (b) reliability analysis step.

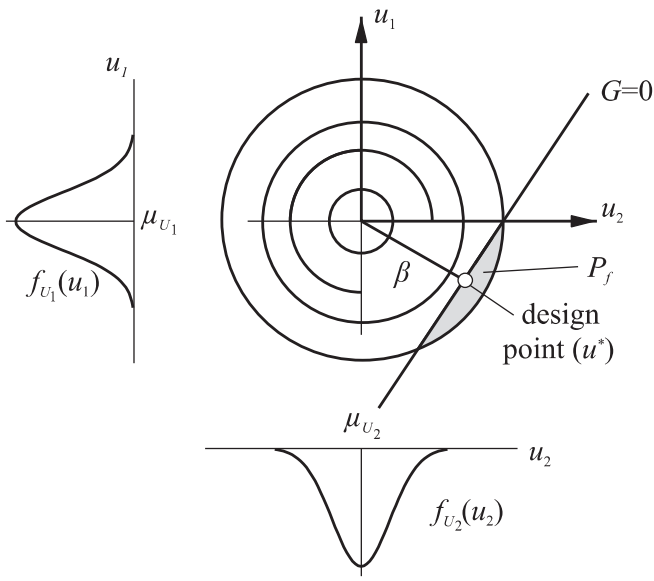

(a)

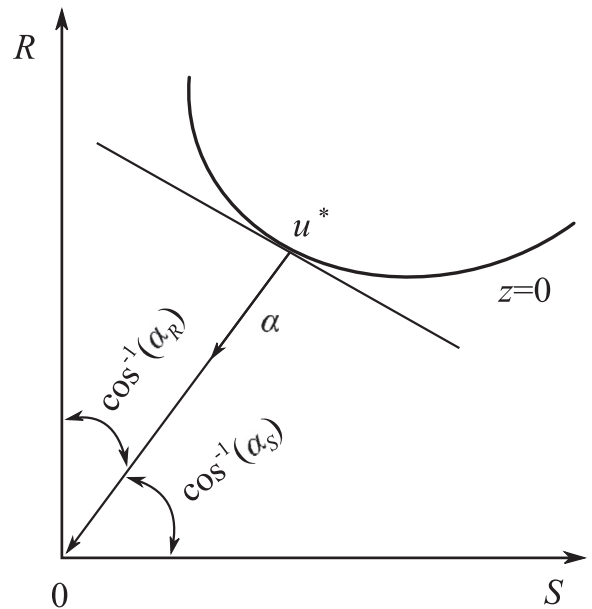

(b)

Fig. 7. (a) Reliability index and design point assuming a linear limit state function, joint density function $\mathrm{f}_{\mathrm{R}, \mathrm{S}}(\mathrm{r}, \mathrm{s})$ of two random variables with marginal density functions $\mathrm{f}_{\mathrm{r}}$ and $\mathrm{f}_{\mathrm{s}}$; and (b) cosines direction at design point. Figure adapted from Schneider [45]. 
failure domain. This point is the so-called design point - see representation in Fig. 7a $\left(r^{*}, s^{*}\right)$ - and its cosines direction measure the importance or sensitivity of each parameter on the probability of failure, where a positive value means that an increase of the mean value also increases safety (see Fig. 7b).

For each time step, the reliability index and probability of failure are iteratively computed according to Fig. 6b. In summary, FORM uses a Taylor expansion in the neighbourhood of the design point that is progressively refined. The response surface method (RSM) is herein applied to approximate the non-linear limit state function by a regression function of lower-order polynomials [43] using selected support points for each random variable. The reliability index is then determined within two iterative cycles, the first uses RSM to compute an approximated limit state function, and the second applies FORM to determine the reliability index for the approximated limit state function. Both are applied sequentially until converging into a design point within a tolerance in absolute value of 0.01 - see Fig. 6 b.

When the reliability of the member reaches the minimum acceptable level of structural safety, the second stage of analysis is initiated to determine the strengthening requirements. This is achieved by computing the area of the CFRP laminate necessary to upgrade the girder from the minimum reliability index of 2.5 (reached after corrosion degradation) to a target reliability index, $\beta_{t}$, of 3.8. This latter value was set according to Steenbergen and Vrouwenvelder [46] for repairing existing highway bridges based on EN 1990 [27]. The same iterative procedure applied in the first stage is again used in the search for the area of the CFRP laminate. It should be mentioned that the area of CFRP laminate is herein treated as deterministic due to the low coefficient of variation associated.

In the third and last stage, another time-dependent reliability analysis is performed to assess the behaviour of the strengthened girder with further degradation. In this stage, both steel corrosion and CFRP laminate degradation are included.

\subsection{Strength limit state}

Given that the structure is a simply supported beam, the formation of a plastic hinge in any section leads to the failure of the girder. Consequently, the reliability analysis can be performed by assessing each segment, in which case failure occurs if any segment fails resulting in a series system. The limit state function, $G$, is formulated for each segment, $j$, as a function of time, $t$ :

$G_{j}(t)=\gamma_{m t l j}(t)-\gamma_{t l_{j}}$

where $\gamma_{m t l}$ is the maximum traffic load scale factor supported by the girder as function of time, and $\gamma_{t l}$ is the standard traffic load scale factor. The first term is time-dependent and is computed from the maximum capacity given by the analytical model described above.

The limit state function can be expressed as:

$G_{j}(t)=\gamma_{m t l_{j}}\left(\theta_{E} ; \nu_{1}(t) ; \nu_{2}(t) ; \nu_{3}(t) ; \ldots, \nu_{n}(t)\right) \times \theta_{R}-\gamma_{t l_{j}}$

where $\theta_{E}$ is the load model uncertainty, $\theta_{R}$ is the resistance model uncertainty, $\nu_{i}$ are the statistical variables, and $n$ is the maximum number of statistical variables described in the next section.

Based on the limit state function defined above, the probability of failure of each segment is given by:

$p_{f_{i}}=\int_{G<0} f\left(\theta_{E} ; \theta_{R} ; \nu_{1}(t) ; \nu_{2}(t) ; \ldots ; \nu_{n}(t)\right)$

where $f$ is the joint density function.

Different segments of the girder are nevertheless correlated as only the level of deterioration varies from section to section. As a first approach, the system probability of failure can be bounded by the probabilities of failure corresponding to independent components (i.e., assumption that the failure of different segments is only determined by corrosion, and thus independent) and to fully correlated segments (i.e., assumption that the corrosion is irrelevant and all segments are fully correlated). The series system probability of failure under the assumption of statistically independent segments is given by:

$P_{f}=1-\prod_{i=1}^{n}\left(1-p_{f i}\right)$

whereas for completely correlated segments, the series system probability of failure is:

$P_{f}=\max \left(p_{f i}\right)$

where $p_{f i}$ is the probability of failure of the $i$-th segment.

The series system probability of failure therefore falls within the following lower and upper bounds limits:

$\max \left(p_{f i}\right) \leqslant P_{f} \leqslant 1-\prod_{i=1}^{n}\left(1-p_{f i}\right)$

For a series system, such limits can be narrowed down using the approach developed by Ditlevsen [47] in which the segments are assumed to be correlated. Accordingly:

$$
\begin{aligned}
\max \left(p_{f i}\right)+\sum_{a=2}^{n} \max \left(p_{f_{a}}-\sum_{b=1}^{a-1} p_{f_{a}} \cap p_{f_{b}} ; 0\right) \leqslant P_{f} \leqslant \\
\sum_{a=1}^{n} p_{f_{a}}-\sum_{a=2, b<a}^{n} \max \left(p_{f_{a}} \cap p_{f_{b}}\right)
\end{aligned}
$$

In the last equation, the lower bound accounts for the individual probabilities, $p_{f_{a}}$, and for all possible joint probabilities involving two segments, i.e., $p_{f_{a}} \cap p_{f_{b}}$. Joint probabilities involving more than two segments are neglected for simplification. The upper bound also includes the individual and joint probabilities, such that the failure events are ordered from the highest probability of failure to the lowest.

The joint probabilities are calculated using the integral of the bivariate normal distribution function written as:

$P\left(p_{f_{1}} \cap p_{f_{2}}\right)=\int_{\beta_{1}}^{\infty} \int_{\beta_{2}}^{\infty} \frac{1}{2 \pi \sqrt{1-\rho_{s y s a b}^{2}}} e^{-\frac{1}{2}\left(1-\rho_{s y y_{a b}}^{2}\right)\left(\beta_{a}^{2} \beta_{b}^{2}-2 \rho_{s y y_{a b}} \beta_{a} \beta_{b}\right)} d \beta_{a} d \beta_{b}$

where $\rho_{s y y_{a b}}$ is the correlation factor between segments $a$ and $b$. The correlation between failure modes $\rho_{s y s_{a b}}$ can be computed as the angle between the vectors connecting the origin and the design points on each failure mode. Since the direction cosine gives the contribution of each random variable to the reliability vector defined by connecting the origin to the design point in the normalised space (see Fig. 7b), the correlation is given by:

$\rho_{s y s_{a b}}=\frac{\operatorname{Cov}(a, b)}{\sigma_{a} \sigma_{b}}=\sum_{k=1}^{n} \alpha_{a_{k}}^{*} \alpha_{b_{k}}^{*}$

where $\alpha_{a_{k}}^{*}$ is the direction cosine at the most probable point of failure and measures the contribution of $a$ over segment $k$. Finally, the reliability of the system can be estimated as the average reliability for both upper and lower bounds shown in Eq. (18).

An example is given in Fig. 8, in which case the segments correlation can be written as:

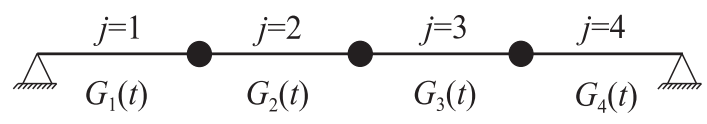

Fig. 8. Series model with four segments. 
$\left\{\begin{array}{l}\rho_{s y s_{12}}=\alpha_{11}^{*} \alpha_{21}^{*}+\alpha_{12}^{*} \alpha_{22}^{*}+\alpha_{13}^{*} \alpha_{23}^{*}+\alpha_{14}^{*} \alpha_{24}^{*} \\ \rho_{s y y_{13}}=\alpha_{11}^{*} \alpha_{31}^{*}+\alpha_{12}^{*} \alpha_{32}^{*}+\alpha_{13}^{*} \alpha_{33}^{*}+\alpha_{14}^{*} \alpha_{34}^{*} \\ \rho_{s y s_{14}}=\alpha_{11}^{*} \alpha_{41}^{*}+\alpha_{12}^{*} \alpha_{42}^{*}+\alpha_{13}^{*} \alpha_{43}^{*}+\alpha_{14}^{*} \alpha_{44}^{*} \\ \rho_{s y y_{23}}=\alpha_{21}^{*} \alpha_{31}^{*}+\alpha_{22}^{*} \alpha_{32}^{*}+\alpha_{23}^{*} \alpha_{33}^{*}+\alpha_{24}^{*} \alpha_{34}^{*} \\ \rho_{\text {sy }_{24}}=\alpha_{21}^{*} \alpha_{41}^{*}+\alpha_{22}^{*} \alpha_{42}^{*}+\alpha_{23}^{*} \alpha_{43}^{*}+\alpha_{24}^{*} \alpha_{44}^{*} \\ \rho_{s y y_{34}}=\alpha_{31}^{*} \alpha_{41}^{*}+\alpha_{32}^{*} \alpha_{42}^{*}+\alpha_{33}^{*} \alpha_{43}^{*}+\alpha_{34}^{*} \alpha_{44}^{*}\end{array}\right.$

The lower and upper probabilities of failure in Fig. 8 are given by:

$P_{f_{\text {lower }}}=p_{f_{1}}+\max \left[p_{f_{2}}-p_{f_{2}} \bigcap p_{f_{1}} ; 0\right]$

$$
+\max \left[p_{f_{3}}-p_{f_{3}} \cap p_{f_{2}}-p_{f_{3}} \cap p_{f_{1}} ; 0\right]+
$$

$+\max \left[p_{f_{4}}-p_{f_{4}} \cap p_{f_{3}}-p_{f_{4}} \cap p_{f_{2}}-p_{f_{4}} \cap p_{f_{1}} ; 0\right]$

and

$$
\begin{gathered}
P_{f_{\text {upper }}}=p_{f_{1}}+p_{f_{2}}+p_{f_{3}}+p_{f_{4}}-p_{f_{2}} \bigcap p_{f_{1}}-\max \left[p_{f_{3}} \cap p_{f_{2}} ; p_{f_{3}} \bigcap p_{f_{1}}\right]+ \\
-\max \left[p_{f_{4}} \bigcap p_{f_{3}} ; p_{f_{4}} \bigcap p_{f_{2}} ; p_{f_{4}} \bigcap p_{f_{1}}\right]
\end{gathered}
$$

The average between the lower and upper probabilities provides a good estimate of the probability of failure in the system based on the work from Barakat, Malkawi [48].

\subsection{Random variables}

In this study, the adopted variables can be divided into three categories: resistance; loads; and corrosion. The resistance variables that contribute to the strength of the girder are: the prestressing strength, $f_{p}$, the CFRP laminate strength, $f_{t}$, and the resistance model uncertainty, $\theta_{R}$. The load variables consist of the traffic load scale factor, $\gamma_{t l}$, the dead loads, $\gamma_{d l}$, the concrete self-weight, $\gamma_{c}$ and the loads model uncertainty, $\theta_{E}$. Additionally, the corrosion variables include the surface chloride concentration, $C_{s}$, threshold chloride concentration, $C_{t h}$, chloride diffusion coefficient, $D_{c l}$, concrete cover, $c$, corrosion rate, $i_{c}$ and corrosion model error, $\gamma_{i c}$. Table 1 summarises the models and values for each variable $[2,4,5,19,49-53]$. It should be mentioned that other material properties not mentioned in the table below, such as the compressive strength of concrete, $f_{c m}$, are considered deterministic with their average design value since they were shown in a previous study not to be significant for the reliability analyses [54].

Several values can be found in the literature for the corrosion rate model, typically varying from 0.1 to $10 \mu \mathrm{A} / \mathrm{cm}^{2}[5-7,31]$. In the scope of this paper, the mean current density adopted is $1.0 \mu \mathrm{A} / \mathrm{cm}^{2}$ based on the work by Dhir, Jones [56] on uncracked concrete specimens exposed to salt spray corresponding to medium corrosion intensity conditions see also [2]. The coefficient of variation is taken as 0.2 from [2,3]. It should be considered that steel corrosion can accelerate CFRP laminate deterioration due to concrete cracking near the reinforcement.
However, this effect is not included in the analyses due to the lack of reliable models for this complex phenomenon. Finally, a normal distribution is considered for the traffic loads according to JCSS [49] with characteristic values, $Q$ [57].

\section{Results and discussion}

\subsection{Reliability analysis of series system}

The probability of failure and reliability index as a function of time for different series reliability assumptions are shown in Fig. 9 for the non-strengthened girder. When the segments are considered statistically independent, the probability of failure is much higher in earlier years. In the case of fully correlated segments, results are similar to the ones obtained with the Ditlevsen bounds, with a good agreement with the lower bound for the earlier years. The contrasting results of fully correlated and independent segments, highlights that such simplifications may not be realistic in practice. Moreover, if the segments are statistically independent, the probability of failure directly corresponds to the weakest segment, which may be too conservative for most cases. Conversely, full correlation means that only the segment subject to higher moment can fail (all other segments have the same strength but smaller applied moments), which represents a reduction in the potential failure modes, and consequently, of the probability of failure. This is further confirmed by analysing Eqs. (15) and (16), which show a much lower probability of failure for fully correlated systems.

The Ditlevsen bounds provide a valid approach to compute the reliability of series systems with correlation between segments. The results presented in Fig. 9 indicate that the upper and lower Ditlevsen bounds are close together and, thus, this approach produces a reliable estimation of the probability of failure of the system. Furthermore, results also indicate that considering statistically independent segments is over conservative since the reliability index computed with this approach is much lower than the one obtained considering correlation between the failure of different segments. Given that the properties of the girder along the beam only change due to corrosion, without it all random variables are constant at different sections except for the applied moment, which is perfectly correlated along the girder. Therefore, the probability of failure obtained for an uncorroded girder corresponds to the midspan segment and that of the fully correlated case. As corrosion progresses, the differences in strength between sections increase causing a reduction in the correlation between the strength of different segments. The system reliability then tends to increase towards the extreme case of uncorrelated random variables. Adopting the average of both bounds can be a good estimate for the contribution of the segments, since it approaches perfect correlation - for up to 50 years - and the statistically independent segments model for the latest years of analysis.

\begin{tabular}{|c|c|c|c|c|c|c|}
\hline Variable & Units & Mean & Standard deviation & $\mathrm{COV}$ & Distribution type & Indicative references \\
\hline Prestressing strength, $f_{p}$ & $\mathrm{MPa}$ & 1,674 & 50 & 0.03 & Normal & {$[51]$} \\
\hline CFRP laminate strength, $f_{t}$ & MPa & 2,687 & 214.9 & 0.08 & Weibull & [55] \\
\hline Resistance model uncertainties, $\theta_{R}$ & - & 1.0 & 0.13 & 0.13 & Log-normal & [49] \\
\hline Traffic loads, $\gamma_{t l}$ & - & 0.78 & 0.117 & 0.15 & Gumbel & {$[22]$} \\
\hline Dead loads, $\gamma_{d l}$ & $\mathrm{kN} / \mathrm{m}$ & 10.83 & 1.08 & 0.10 & Normal & {$[52]$} \\
\hline Concrete self-weight, $\gamma_{c}$ & $\mathrm{kN} / \mathrm{m}^{3}$ & 25.0 & 1.0 & 0.04 & Normal & [49] \\
\hline Load model uncertainties, $\theta_{E}$ & - & 1.05 & 0.11 & 0.10 & Log-normal & [49] \\
\hline Surface chloride concentration, $C_{s}$ & $\mathrm{~kg} / \mathrm{m}^{3}$ & 0.35 & 0.175 & 0.50 & Normal & {$[53]$} \\
\hline Threshold for chloride concentration, $C_{t h}$ & $\mathrm{~kg} / \mathrm{m}^{3}$ & 1.2 & 0.228 & 0.19 & Normal & [53] \\
\hline Chloride diffusion coefficient, $D_{c d}$ & $\mathrm{~cm}^{2} / \mathrm{s}$ & $2.0 \times 10^{-8}$ & $4.0 \times 10^{-9}$ & 0.20 & Normal & [53] \\
\hline Cover, $c$ & $\mathrm{~cm}$ & 5.0 & 0.75 & 0.15 & Log-normal & [19] \\
\hline Corrosion rate, $i_{c}$ & $\mu \mathrm{A} / \mathrm{cm}^{2}$ & 1.0 & 0.20 & 0.20 & Log-normal & {$[2-4,56]$} \\
\hline Model error, $\gamma_{i c}$ & - & 1.0 & 0.20 & 0.20 & Normal & [19] \\
\hline
\end{tabular}

Table 1

Statistical properties of random variables used in time-dependent reliability analysis. 

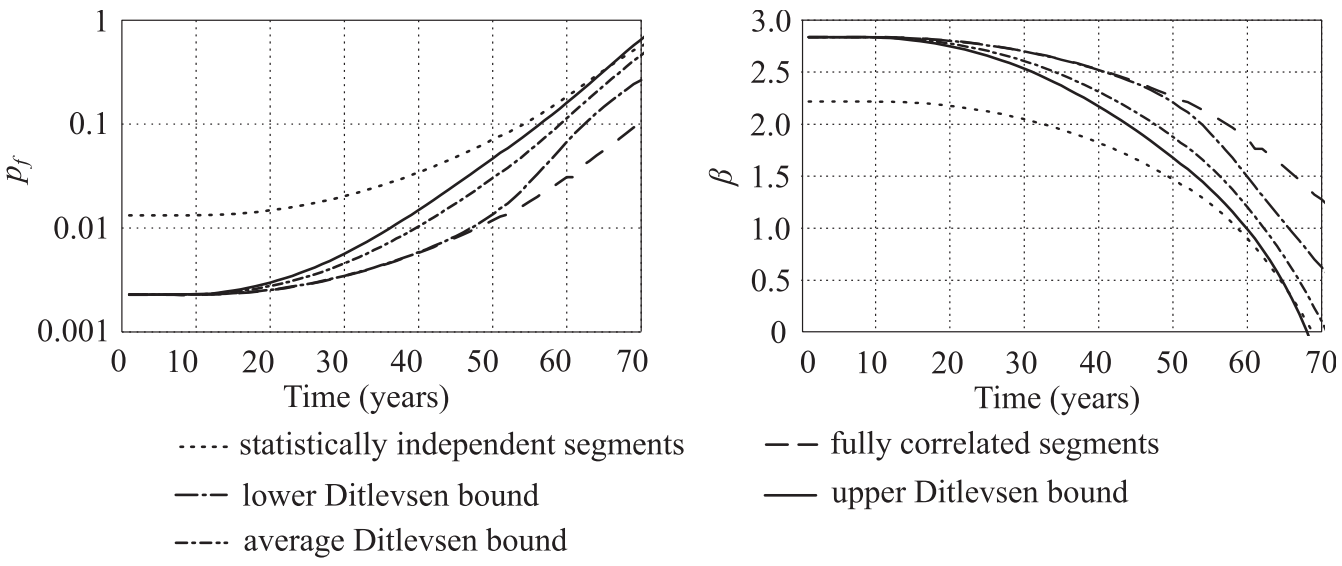

- - fully correlated segments

— upper Ditlevsen bound
Fig. 9. Probability of failure $\left(P_{f}\right)$ and reliability index $(\beta)$ as a function of time for different series reliability approaches.

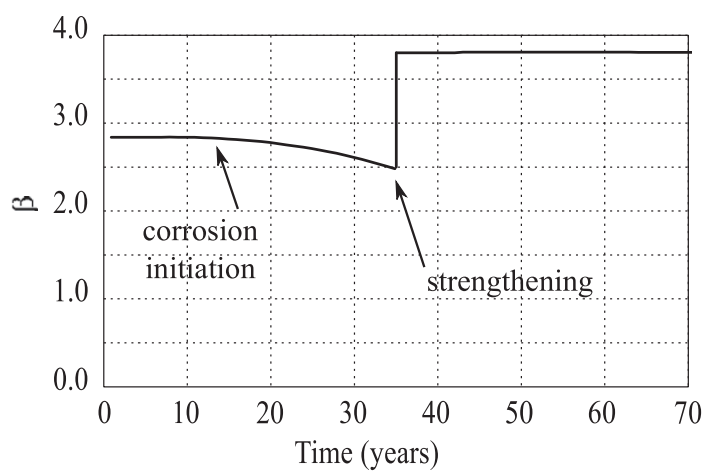

Fig. 10. Reliability index as a function of time for strengthened section without CFRP laminate degradation.

\subsection{Time-dependent reliability analysis}

The time-dependent safety without considering the CFRP laminate degradation is illustrated in Fig. 10. It is important to denote that the reliability index starts close to 2.8 . When the safety of the girder designed according to the old standard is assessed using the requirements imposed by EN 1991-2 [28], the structural safety is already below the minimum allowed by the new standard and very close to the threshold of unacceptable safety of 2.5 discussed above. This result is explained by the differences in the traffic load models - see comparison in Appendix A. Corrosion starts at 11 years of age, but only becomes severe after 20 years. Without strengthening, the reliability of the girder would reach zero, corresponding to a $50 \%$ probability of failure, after 70 years of age. After the chloride corrosion starts, the rate of reduction of the reliability index increases.

The strengthening area of CFRP laminates required to increase the

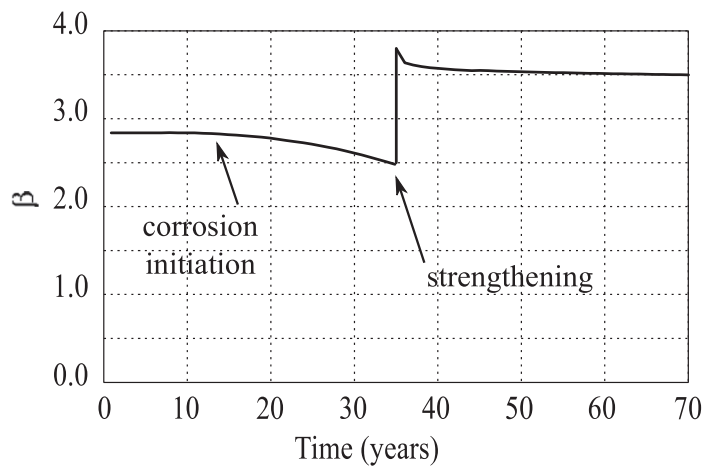

Fig. 11. Reliability index as a function of time for strengthened section with CFRP laminate degradation. reliability index to 3.8 calculated using the procedure described in the previous section is $305 \mathrm{~mm}^{2}$. After strengthening, further reductions of the reliability index factor due to degradation are significantly slower (Fig. 10).

When the CFRP laminate degradation is taken into account - see Fig. 11 - the reliability progressively reduces over the years after strengthening. However, this impact is not as severe as the one caused by corrosion [18].

\subsection{Sensitivity analysis}

The cosines direction at the design point for each random variable as a function of time are represented in Fig. 12. Values close to zero indicate the variable not to be relevant in the analysis, whereas cosines closer to 1 or -1 correspond, respectively, to a significant negative or positive impact. A representation of the geometric meaning can also be found in Fig. 7b.

From Fig. 12, it can be concluded that traffic loads, $\gamma_{t l}$, have the highest weight in the analysis reaching a value close to 0.7 . However, this role is reduced with the development of corrosion. The uncertainties for both resistance and load models, $\theta_{R}$ and $\theta_{s}$, have cosine values close to -0.44 and 0.54 , respectively, and decrease with corrosion. The large cosine values without corrosion indicate that a significant part of the uncertainty is associated with the limitations of the models employed. With the growth of corrosion, the uncertainty associated with this variable becomes increasingly significant and, consequently, the importance of the uncertainty in models reduces. The prestressing strength, $f_{p}$, presents values close to 0.16 over the entire analysis, the concrete self-weight, $\gamma_{c}$, and the dead loads, $\gamma_{d l}$, present

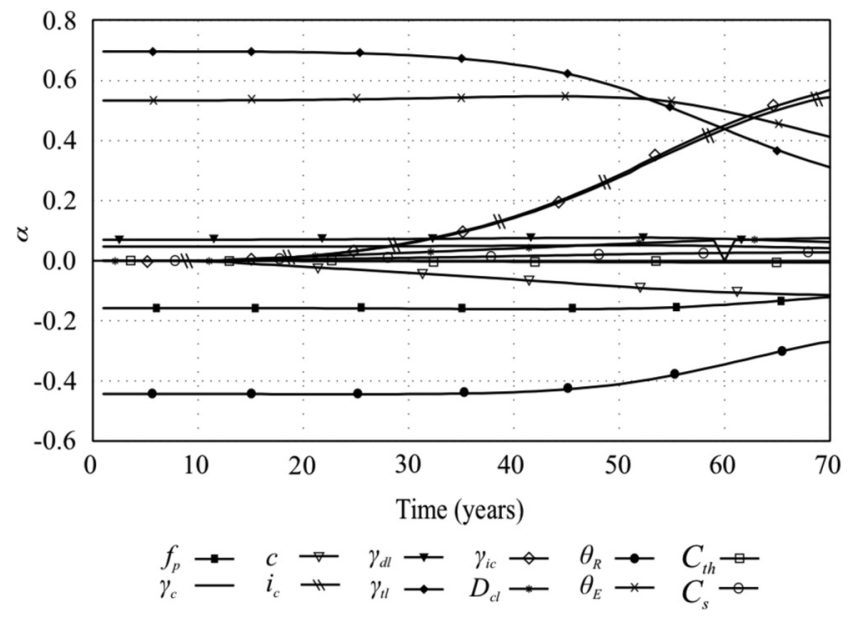

Fig. 12. Cosines direction at design points as a function of time. 


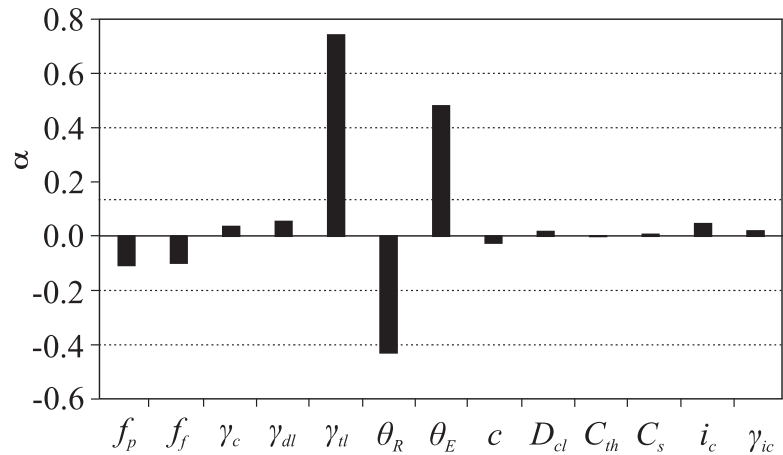

Fig. 13. Cosines direction at design point for the strengthened girder.

values close to -0.08 . The remaining variables, surface chloride concentration, $C_{s}$, threshold chloride concentration, $C_{t h}$, chloride diffusion and coefficient, $D_{c l}$, have no contribution without corrosion. With the ageing of the structure, the reduction in strength due to corrosion becomes more likely, and the importance of those parameters increase, as shown in Fig. 12. Therefore, after the initiation of corrosion, the most important variables related with this process of degradation are the concrete cover, $c$, corrosion model error, $\gamma_{i c}$, and corrosion rate, $i_{c}$. Their importance starts to increase with the development of corrosion, reaching values of respectively to -0.12 and 0.60 after 60 years.

After the strengthening of the member, the equilibrium in the cosines direction changes due to the recovered flexural strength (see Fig. 13). Consequently, the traffic load, $\gamma_{t l}$, increases its importance relatively to the values observed in early years, whereas the concrete cover, $c$, and corrosion rate, $i_{c}$, decrease its weight to values close to the ones before the initiation of corrosion. The CFRP laminate strength, $f_{f}$, assumes a weight of -0.10 . All other calculated values remain practically constant over time since the degradation is quite slow (see Fig. 10).

\section{Summary and conclusions}

This paper presented a time-dependent reliability analysis of prestressed concrete girders. The girders were subjected to a scenario of degradation caused by pitting corrosion. The rehabilitation of the member was done using externally bonded CFRP laminates after the girder reached an unacceptable probability of failure. It was also assumed that the CFRP laminate could degrade over time after rehabilitation.
The reliability analysis procedure proposed in this paper included the effects of both spatial and temporal corrosion. The spatial distribution of corrosion was analysed by considering the reinforcement divided in segments on a series system. The obtained results showed the reliability index to be more conservative when the segments are considered statistically independent. In addition, the assumption of fully correlated and statistically independent segments can produce contrasting results, which may fail to properly predict the structural behaviour. The first approach is suited for analysis while the girder is uncorroded. In this situation, the strength along the girder does not vary, in which case failure is directly driven by the midspan segment given that it is subjected to the highest applied moment (all segments are fully correlated). The second approach provides good results when corrosion is significantly advanced, since the differences in the strength of segments can cause failure in other regions other than the midspan of the girder, being theoretically driven by the weakest element. For all other steps of analysis, which correspond to 50 years of analysis, neither approach (i.e. fully correlated and statistically independent segments) provides good estimates. In this case, the Ditlevsen bounds are recommended given that they can approximate the model with perfect correlation in the first 50 years of analysis, and the statistically independent segments model in the following years.

Results from time-dependent reliability analysis also showed that the degradation of the CFRP laminates does not impact on the reliability as significantly as corrosion. The sensitivity analysis for the nondeterminist variables showed the traffic loads, models uncertainties and corrosion rate and uncertainty to be the most relevant variables, followed by prestressing strength and concrete cover. The significance of variables, however, changes over time and also with the conditions of the structure. For example, corrosion rate and concrete cover increase importance with the development of corrosion, and traffic loads lose weight. After strengthening the girder, the reinforcement steel is no longer critical to the strength and, consequently, the impact of corrosion on the probability of failure is much lower than that observed for the unstrengthened girder.

\section{Acknowledgements}

D. Dias-da-Costa would like to acknowledge the support from the Australian Research Council through the Discovery Early Career Researcher Award (DE150101703) and Linkage project (LP140100591). The third author acknowledges the financial support of the Portuguese Science and Technology Foundation (FCT) through the PhD grant number SFRH/BD/76345/2011.

\section{Appendix A. Comparison of traffic load models}

This section presents a summary of the traffic load models from RSA [24] and EN 1991-2 [28] applied to the bridge geometry used in the case study presented in this paper. The traffic loads defined in RSA [24] were developed in the 1960s and include two load models - see Figs. A1 and A2. The first sets three concentrated loads that account for an idealised three-axle vehicle and its dynamic effects, whereas the second model defines a uniformly distributed load and a knife load. Loads are to be placed at the most unfavourable positions along the bridge deck for the design of each structural element and their characteristic values are shown in Table A1. The principal load model LM1 defined in the EN 1991-2 [28] is shown in Fig. A2 and the characteristic values are given in Table A2. Distributed loads are to be placed in lanes of $3 \mathrm{~m}$ across the deck width, whereas concentrated loads are also included to account for an idealised two-axle vehicle and its dynamic effects.

For the same bridge deck, a comparison of ultimate design bending moments is shown as a function of the span in Fig. A3. Please note that the
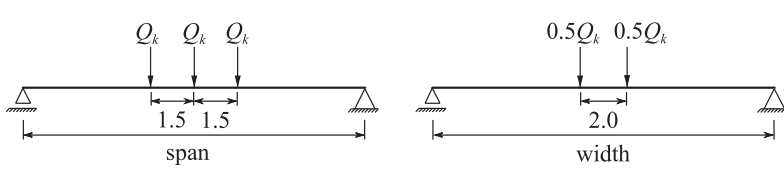

(a)
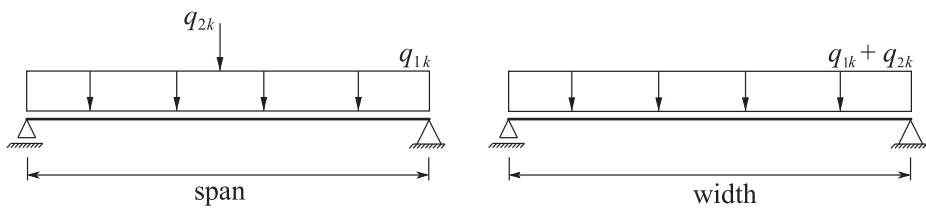

(b)

Fig. A1. Traffic load models in RSA [24]: (a) idealised vehicle; and (b) knife and distributed load models. 

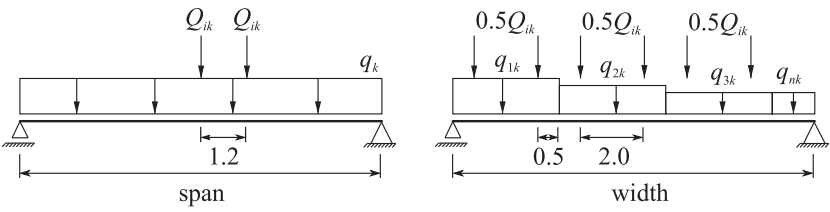

Fig. A2. Traffic load model LM1 in EN 1991-2 [28] (dimensions in 'm').

Table A1

Characteristic values defined in RSA [24].

\begin{tabular}{lll}
\hline Concentrated load $\underline{Q}_{k}(\mathrm{kN})$ & $\begin{array}{l}\text { Distributed load } q_{1 k}(\mathrm{kN} / \\
\left.\mathrm{m}^{2}\right)\end{array}$ & $\begin{array}{l}\text { Knife load } q_{2 k}(\mathrm{kN} / \\
\mathrm{m})\end{array}$ \\
\hline 200 & 4 & 50 \\
\hline
\end{tabular}

Table A2

Characteristic values defined in EN 1991-2 [28].

\begin{tabular}{lll}
\hline Location & Concentrated loads $\underline{Q_{i k}(\mathrm{kN})}$ & Distributed load $q_{i k}\left(\mathrm{kN} / \mathrm{m}^{2}\right)$ \\
\hline Lane 1 & 300 & 9 \\
Lane 2 & 200 & 2.5 \\
Lane 3 & 100 & 2.5 \\
Other lanes, n & 0 & 2.5 \\
Remaining areas & 0 & 2.5 \\
\hline
\end{tabular}

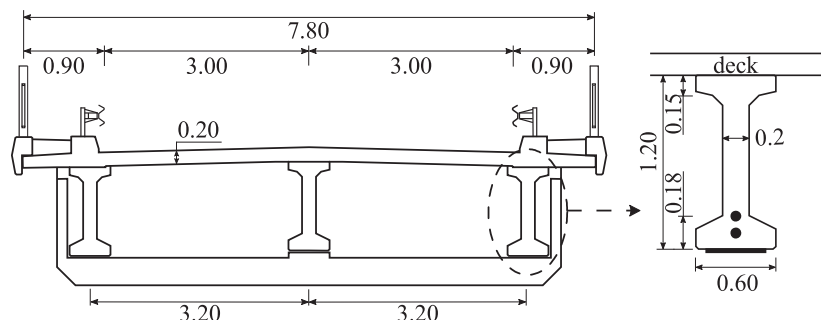

(a)

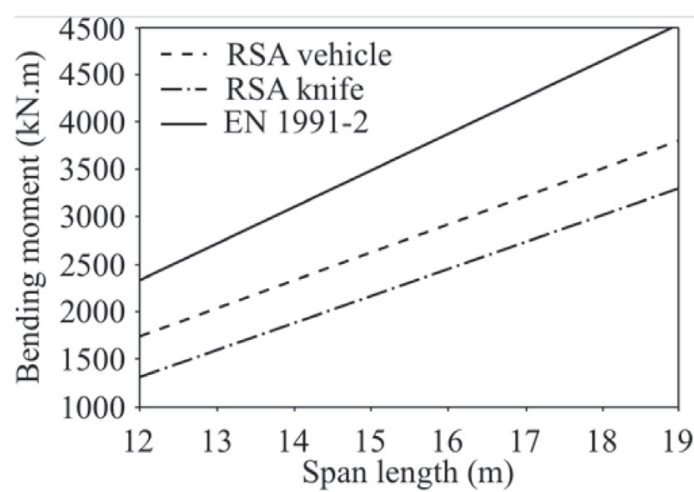

(b)

Fig. A3. Comparison between codes: (a) bridge cross-section; (b) ultimate design bending moment.

dead load includes self-weight, sidewalks, guard rail and asphalt corresponding to the layout shown in the figure. As can be concluded, the design bending moment from the current standard, EN 1991-2 [28], is significantly higher than the one provided by both models in RSA [24].

\section{References}

[1] ACI Committee 222. Protection of metals in concrete against corrosion. ACI 222R01, American Concrete Institute; 2001.

[2] Stewart MG, Rosowsky DV. Time-dependent reliability of deteriorating reinforced concrete bridge decks. Struct Saf 1998;20:91-109.

[3] Val DV, Melchers RE. Reliability of deteriorating RC slab bridges. J Struct Eng 1997; 123:1638-44.

[4] Val DV, Stewart MG, Melchers RE. Effect of reinforcement corrosion on reliability of highway bridges. Eng Struct 1998;20:1010-9.

[5] Vu KAT, Stewart MG. Structural reliability of concrete bridges including improved chloride-induced corrosion models. Struct Saf 2000;22:313-33.

[6] Stewart MG. Spatial variability of pitting corrosion and its influence on structural fragility and reliability of RC beams in flexure. Struct Saf 2004;26:453-70.

[7] Darmawan MS, Stewart MG. Effect of pitting corrosion on capacity of prestressing wires. Mag Concr Res 2007;59:131-9.

[8] Stewart MG, Al-Harthy A. Pitting corrosion and structural reliability of corroding RC structures: Experimental data and probabilistic analysis. Reliab Eng Syst Saf 2008;93:373-82.

[9] Stewart MG, Mullard JA. Spatial time-dependent reliability analysis of corrosion damage and the timing of first repair for RC structures. Eng Struct 2007;29:1457-64.

[10] Stewart MG, Suo Q. Extent of spatially variable corrosion damage as an indicator of strength and time-dependent reliability of RC beams. Eng Struct 2009;31:198-207.

[11] Stewart MG. Spatial and time-dependent reliability modelling of corrosion damage, safety and maintenance for reinforced concrete structures. Struct Infrastruct Eng 2012;8:607-19.

[12] Val DV. Deterioration of strength of RC beams due to corrosion and its influence on beam reliability. J Struct Eng 2007;133:1297-306.

[13] Stewart MG. Mechanical behaviour of pitting corrosion of flexural and shear reinforcement and its effect on structural reliability of corroding RC beams. Struct Saf 2009;31:19-30.

[14] Leeming MB, Hollaway LC. Strengthening of reinforced concrete structures. Woodhead Publishing Limited; 1999.

[15] Kim YJ, Kang J-Y, Park J-S, Jung W-T. Condition assessment of corrosion-damaged bridge girders strengthened with post-tensioned composite strips. J Phys Conf Ser 2017;842:012031.

[16] Liu Y, Peng H, Cai CS. A probabilistic model for the flexural capacity of reinforced concrete structures strengthened with prestressed CFRP plates. Adv Struct Eng 2015;18:629-42.

[17] Firouzi A, Taki A, Mohammadzadeh S. Time dependent reliability analysis of concrete transportation infrastructure shear strengthened by CFRP wraps. In: Proceedings of the world congress on engineering and computer science $2016 \mathrm{Vo}$ II, WCECS 2016, October 19-21, 2016, San Francisco, USA2016.

[18] Ali O, Bigaud D, Ferrier E. Comparative durability analysis of CFRP-strengthened RC highway bridges. Constr Build Mater 2012;30:629-42.

[19] Bigaud D, Ali O. Time-variant flexural reliability of RC beams with externally 
bonded CFRP under combined fatigue-corrosion actions. Reliab Eng Syst Saf 2014;131:257-70.

[20] Guo T, Chen Z, Liu T, Han D. Time-dependent reliability of strengthened PSC boxgirder bridge using phased and incremental static analyses. Eng Struct 2016;117:358-71.

[21] Aashto LRFD. Load and resistance factor bridge design specifications. American Association of State Transportation and Communication 1994.

[22] Wiśniewski DF, Casas JR, Ghosn M. Codes for safety assessment of existing bridges_current state and further development. Struct Eng Int 2012;22:552-61.

[23] REBAP. Regulamento de estruturas de betão armado e pré-esforçado. Ministério da Habitação, Obras Públicas e Transportes; 1985.

[24] RSA. Regulamento de segurança e acções para estruturas de edifícios e pontes. Obras Públicas e Transportes: Ministério da Habitação; 1983.

[25] EN 1992-1-1. Eurocode 2: Design of concrete structures - Part 1-1: General rules and rules for buildings. CEN (European Committee for Standardization), Brussels; 2004.

[26] prEN 10138-3. Prestressing steels - Part 3: Strand. CEN (European Committee for Standardization), Brussels; 2000.

[27] EN 1990. Eurocode 0: Basis of structural design. CEN (European Committee for Standardization), Brussels; 2002.

[28] EN 1991-2. Eurocode 1: Actions on structures- Part 2: Traffic loads on bridges. CEN (European Committee for Standardization), Brussels; 2002.

[29] EN 1992-2. Eurocode 2: Design of concrete structures - Part 2: Concrete bridges Design and detailing rules. CEN (European Committee for Standardization), Brussels; 2005.

[30] Dias-da-Costa D, Graça-e-Costa R, Ranzi G, Smith ST. Assessment of the behavior of FRP-strengthened RC slabs using a discrete crack model. J Compos Constr 2018;22:04018045.

[31] Darmawan MS, Stewart MG. Spatial time-dependent reliability analysis of corroding pretensioned prestressed concrete bridge girders. Struct Saf 2007;29:16-31.

[32] Val DV, Trapper PA. Probabilistic evaluation of initiation time of chloride-induced corrosion. Reliab Eng Syst Saf 2008;93:364-72.

[33] Abanilla MA, Karbhari VM, Li Y. Interlaminar and intralaminar durability characterization of wet layup carbon/epoxy used in external strengthening. Compos B Eng 2006;37:650-61.

[34] Abanilla MA, Li Y, Karbhari VM. Durability characterization of wet layup graphite/ epoxy composites used in external strengthening. Compos B Eng 2005;37:200-12.

[35] David E, Neuner JD. Environmental durability studies for FRP systems: definition of normal conditions of use of FRP for structural strengthening applications. FRP Composites in Civil Engineering. Hong Kong: Elsevier; 2001.

[36] Karbhari VM, Chin JW, Hunston D, Benmokrane B, Juska T, Morgan R, et al. Durability gap analysis for fiber-reinforced polymer composites in civil infrastructure. J Compos Constr 2003;7:238-47.

[37] Liao K. In-situ strength degradation of glass fibers in a pultruded composite by environmental aging. J Mater Sci Lett 1999;18:763-5.
[38] Rivera J, Karbhari VM. Cold-temperature and simultaneous aqueous environment related degradation of carbon/vinylester composites. Compos B Eng 2002;33:17-24.

[39] Karbhari VM, Abanilla MA. Design factors, reliability, and durability prediction of wet layup carbon/epoxy used in external strengthening. Compos B Eng 2007;38:10-23.

[40] AASHTO. Manual for bridge evaluation. American Association of State Transportation and Communication; 2008.

[41] Moses F. NCHRP Report 454: Calibration of load factors for LRFR bridge evaluation. Washington, DC: TRB National Research Council; 2001.

[42] Melchers RE. Structural reliability analysis and prediction. 3rd ed. Wiley; 2017.

[43] Bucher C. Computational analysis of randomness in structural mechanics: Structures and infrastructures book series, volume 3; 2009.

[44] FERUM. Finite element reliability using matlab. http://www.ifma.fr/FERUM; 2010.

[45] Schneider J. Introduction to safety and reliability of structures. International Association for Bridge and Structural Engineering, Zurich, Switzerland; 1997.

[46] Steenbergen RDJM, Vrouwenvelder ACWM. Safety philosophy for existing structures and partial factors for traffic loads on bridges. Heron 2010;2:123-40.

[47] Ditlevsen O. Narrow reliability bounds for structural systems. J Struct Mech 1979;7:453-72.

[48] Barakat SA, Malkawi AIH, Tahat ReH. Reliability-based optimization of laterally loaded piles. Struct Saf 1999;21:45-64.

[49] JCSS PMC, 2001. Probabilistic Model Code; 2001.

[50] Wisniewski DF. Safety formats for the assessment of concrete bridges. Portugal: University of Minho; 2007.

[51] Jacinto L, Pipa M, Neves LAC, Santos LO. Probabilistic models for mechanical properties of prestressing strands. Constr Build Mater 2012;36:84-9.

[52] Vejdirektoratet. Reliability-based classification of the load carrying capacity of existing bridges. Technical Report Report 291, Ministry of Transport2004.

[53] Bastidas-Arteaga E, Bressolette P, Chateauneuf A, Sánchez-Silva M. Probabilistic lifetime assessment of RC structures under coupled corrosion-fatigue deterioration processes. Struct Saf 2009;31:84-96.

[54] Gomes S, Neves L, Dias-da-Costa D, Fernandes P, Júlio E. Probabilistic analysis of high strength concrete girders strengthened with CFRP. Vulnerability, uncertainty, and risk: quantification, mitigation, and management, United Kingdom; 2014. p. 1274-82.

[55] Gomes S, Dias-da-Costa D, Neves LAC, Hadigheh SA, Fernandes P, Júlio E. Probabilistic-based characterisation of the mechanical properties of CFRP laminates. Constr Build Mater 2018;169:132-41.

[56] Dhir RK, Jones MR, McCarthy MJ. PFA concrete: chloride-induced reinforcement corrosion. Mag Concr Res 1994;46:269-77.

[57] von Scholten C, Vejdirektoratet D. Reliability-based classification of the load carrying capacity of existing bridges: the Directorate; 2004. 